\title{
Metal ion binding with dehydroannulenes - Plausible two-dimensional molecular sieves
}

\author{
B SATEESH, Y SOUJANYA and G NARAHARI SASTRY* \\ Molecular Modeling Group, Organic Chemical Sciences, Indian Institute of Chemical Technology, \\ Hyderabad 500007 \\ e-mail: gnsastry@iict.res.in
}

MS received 13 July 2007; accepted 23 July 2007

\begin{abstract}
Theoretical investigations have been carried out at B3LYP/6-311++G** level of theory to study the binding interaction of various metal ions, $\mathrm{Li}^{+}, \mathrm{Na}^{+}$and $\mathrm{K}^{+}$with dehydroannulene systems. The present study reveals that alkali metal ions bind strongly to dehydroannulenes and the passage through the central cavity is controlled by the size of metal ion and dimension of dehydroannulene cavity.
\end{abstract}

Keywords. Alkali metals; dehydroannulenes; binding energy; penetration barrier.

\section{Introduction}

Replacement of one-third of carbon-carbon bonds of graphite with ethyne units results in the formation of the planar networks graphyne ${ }^{1}$ and graphdiyne ${ }^{2}$ composed of phenyl rings and triple bonds, which are synthetically approachable allotropes of carbon and carbon networks based on dehydrobenzoannulene $e^{3-6}$ (DBA). Current interest in this class of compounds is partly due to their ability to model sections of expanded carbon networks such as graphyne and graphdiyne, fullerenes, nanotubes and related strained ring systems. ${ }^{7}$ Synthetic chemistry attempts towards dehydroannulenes macromolecules have been met with tremendous success in recent years. ${ }^{8-14}$ The structural uniqueness of these class of molecules is likely to have several applications in the areas spanning catalytic, magnetic, optical switches, photochromic, nonlinear optical materials, liquid crystals, thin-film transistors, optical storage devices, ${ }^{15}$ etc.

Because of the size of the systems it is not computationally viable to understand the passage of metal ion through the carbon $\pi$-networks. However, one can study at the molecular level the degree of metal ion interaction with model sections of expanded carbon networks. Our recent work in the study of cation$\pi^{16-22}$ interactions has improved our ability to understand this fundamental property of metal ion interactions. In the present study we have employed quantum

\footnotetext{
*For correspondence
}

mechanical calculations to obtain reliable estimates of the binding affinities of metal ions such as $\mathrm{Li}^{+}$, $\mathrm{Na}^{+}$and $\mathrm{K}^{+}$to the four model systems namely dehydro [12]annulene (1), dehydrobenzoannulene (2), dehydropyridoannulene (3) and dehydro[18]annulene (4), given in the scheme 1 . Our objective in this study was to explore prospect of alkali metals as the sieving agents. Since the interaction of the metal ion with dehydroannulene is highly dependent upon the nature of $\pi$-network and the cavity size, in the present study we have considered four different types of dehydroannulenes, among them three are dehydro[12] annulene and one is dehydro[18]annulene.

\section{Computational details}

The dehydroannulene systems and their metal complexes were optimized at B3LYP/6-31G* level of theory. Frequency calculations were then performed to ascertain the nature of resultant stationary point obtained and also to obtain the zero-point vibrational energy corrections. Single point calculations were done using $6-311++\mathrm{G}^{* *}$ basis set on $6-31 \mathrm{G}^{*}$ optimized geometries at the same level of theory. Binding energies are calculated using the formula $\left[E_{\text {complex }}-\right.$ $\left.\left(E_{\mathrm{M}}{ }^{+}+E_{\text {dehydroannulene }}\right)\right]$. Binding energy differences of the transition state (TS) structure and corresponding minimum energy structure is called as metal ion transfer energy barrier (penetration barrier). All the calculations were done using Gaussian $03^{23}$ suite of program. A natural bond orbital (NBO) analysis ${ }^{24}$ 


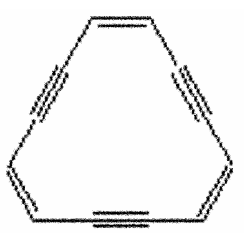

1

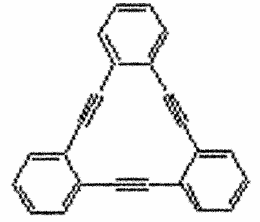

2

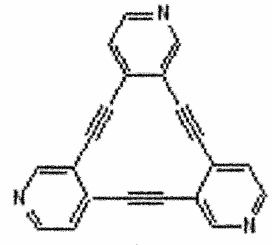

3

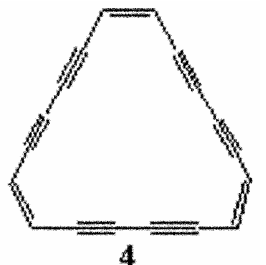

4

Scheme 1. Dehydroannulene considered in the study.

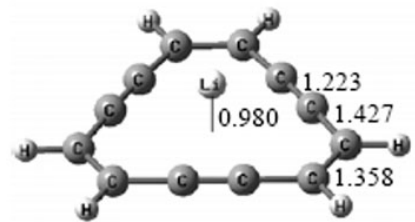

1- $\mathbf{L i}^{+}(0), \mathrm{C}_{3 \mathrm{v}}$

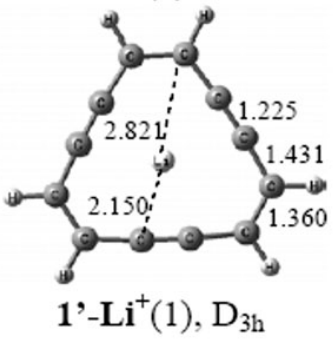

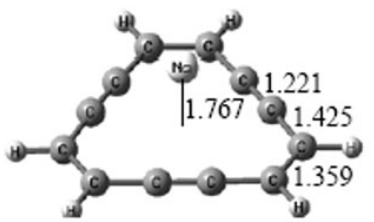

$1-\mathrm{Na}^{+}(0), \mathrm{C}_{3 \mathrm{v}}$

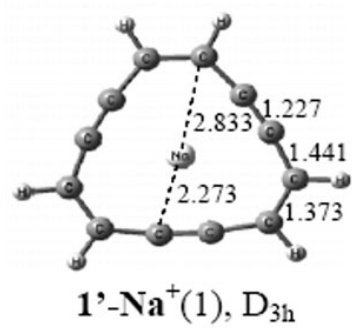

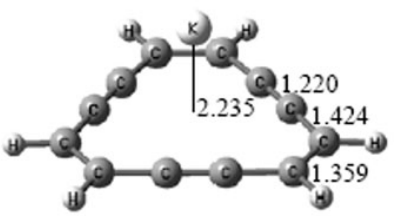

$1-\mathbf{K}^{+}(0), C_{3 v}$

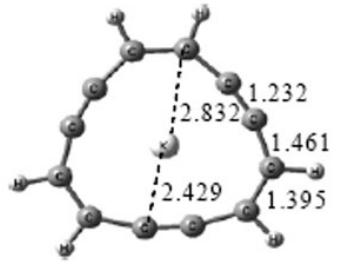

$\mathbf{1}^{\prime}-\mathrm{K}^{+}(1), \mathrm{D}_{3 \mathrm{~h}}$

Figure 1. B3LYP/6-31G* optimized geometries, NIMAG in parenthesis, point groups of $\mathbf{1}-\mathbf{M}^{+}$and $\mathbf{1}^{\prime}-\mathbf{M}^{+}$complexes.

was invoked using the population keyword in Gaussian 03.

\section{Results and discussion}

In the present study we have considered two different binding modes of the metal to the dehydroannulene systems. In these metal ion complexes, we have placed the metal ion at the centre of the cavity $\left(\mathbf{1}^{\prime}-\mathbf{M}^{+}, \mathbf{2}^{\prime}-\mathbf{M}^{+}\right.$, $\mathbf{3}^{\prime}-\mathbf{M}^{+}, \mathbf{4}^{\prime}-\mathbf{M}^{+}$) and the other above the plane of the principal axis of the cavity $\left(\mathbf{1}-\mathbf{M}^{+}, \mathbf{2}-\mathbf{M}^{+}, \mathbf{3}-\mathbf{M}^{+}, \mathbf{4}-\right.$ $\mathbf{M}^{+}$). In the first case, all the complexes were found to be first order saddle point except $\mathbf{4}^{\prime}-\mathbf{L i}^{+}$and $\mathbf{4}^{\mathbf{}}-\mathbf{N a}^{+}$ complex. While in the second case, metal ioncomplexes are found to be minima on the potential energy surface (PES) except $\mathbf{4}-\mathbf{L i}^{+}$and $\mathbf{4}-\mathbf{N a}^{+}$complex. Metal ion complexes of all the dehydroannulenes considered in the present study and their geometrical parameters along with number of imaginary frequencies (NIMAG) and point groups are depicted in figures 1-4. Binding energies $(\mathrm{kcal} / \mathrm{mol})$ obtained at B3LYP/6-311++G** level of theory are given in table 1.
As evident from this table 1 the binding affinity of alkali metal ion towards the cavity of dehydroannulune is in the order $\mathrm{Li}^{+}>\mathrm{Na}^{+}>\mathrm{K}^{+}$. And $\mathrm{Li}^{+}$shows strong binding to dehydoannulene cavity at a distance of $0.980 \AA, \mathrm{Na}^{+}$at $1.767 \AA$ and $\mathrm{K}^{+}$at $2.235 \AA$. Irrespective of nature of carbon network, (1-3) $\mathrm{Li}^{+}$complex is found to exhibit strong binding affinity. The cavity sizes of the 1-3 dehydroannulene metal ion complexes are gauged through the distances between the parallel edges of the $\mathrm{C}_{3}$ symmetric central scaffold which are 2.821, 2.867 and 2.858 A respectively. Considering two binding modes, always the metal-complex with ion positioned above the plane of the principal axis of the cavity is showing higher interaction energies. For example, 1- $\mathbf{L i}^{+}$complex has highest interaction energy of $-50.6 \mathrm{kcal} / \mathrm{mol}$ at B3LYP/6-311++G** level and is $128.0 \mathrm{kcal} / \mathrm{mol}$ more than $\mathbf{1}^{\prime}-\mathbf{K}^{+}$complex. Understandably, the binding energy of metal complexes decreases with increase in the size of the metal ion, in accordance with earlier results. ${ }^{16,21}$

Placement of the metal ions at the centroid of the dehydroannulenes did not lead to stationary points 

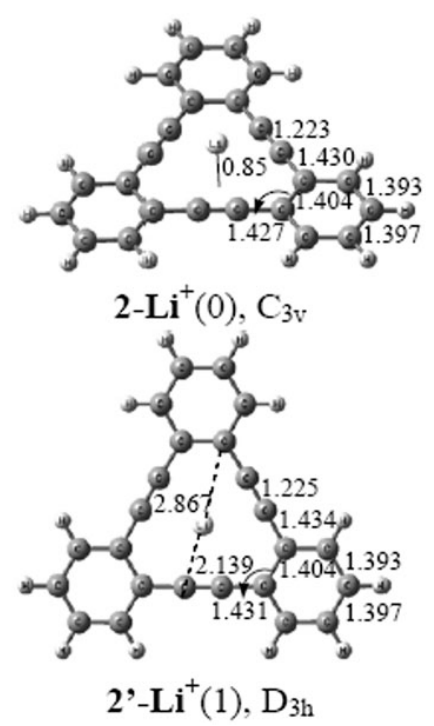

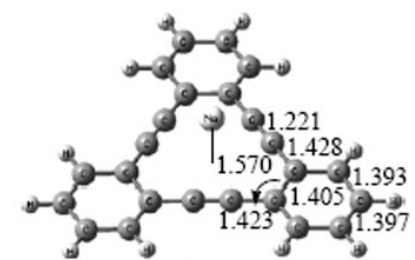

$2-\mathrm{Na}^{+}(0), \mathrm{C}_{3 \mathrm{v}}$

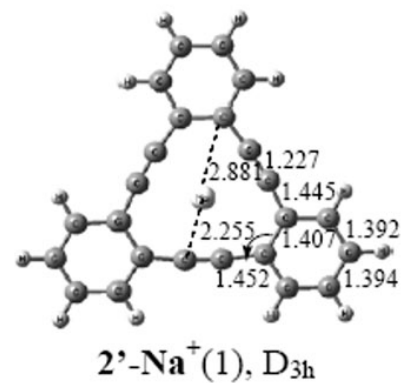

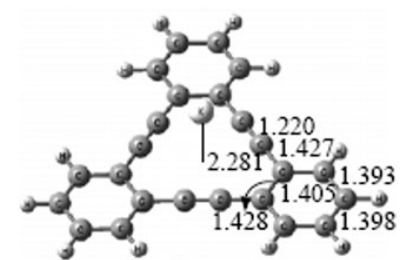

$2-\mathbf{K}^{+}(0), \mathrm{C}_{3 \mathrm{v}}$

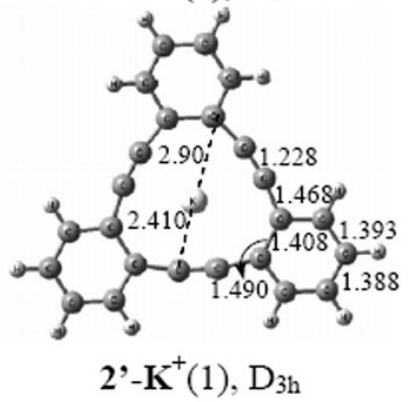

Figure 2. B3LYP/6-31G* optimized geometries, NIMAG in parenthesis, point groups of 2- $\mathbf{M}^{+}$and $\mathbf{2}^{\prime}-\mathbf{M}^{+}$complexes.

Table 1. Binding energies $(\mathrm{kcal} / \mathrm{mol})$ of all the metal ion complexes obtained at B3LYP/6-311++G** level of theory.

\begin{tabular}{lcrr}
\hline & $\mathrm{Li}^{+}$ & $\mathrm{Na}^{+}$ & \multicolumn{1}{c}{$\mathrm{K}^{+}$} \\
\hline $\mathbf{1}-\mathbf{M}^{+}$ & $-50 \cdot 6$ & $-34 \cdot 2$ & $-22 \cdot 8$ \\
$\mathbf{1}^{\prime}-\mathbf{M}^{+}$ & $-47 \cdot 3$ & $1 \cdot 2$ & $77 \cdot 4$ \\
$\mathbf{2}-\mathbf{M}^{+}$ & $-61 \cdot 7$ & $-43 \cdot 2$ & $-29 \cdot 9$ \\
$\mathbf{2}^{\prime}-\mathbf{M}^{+}$ & $-58 \cdot 9$ & $-7 \cdot 4$ & $73 \cdot 6$ \\
$\mathbf{3}^{+} \mathbf{M}^{+}$ & $-47 \cdot 1$ & $-30 \cdot 1$ & $-18 \cdot 7$ \\
$\mathbf{3}^{\prime}-\mathbf{M}^{+}$ & $-43 \cdot 9$ & $5 \cdot 6$ & $85 \cdot 3$ \\
$\mathbf{4}-\mathbf{M}^{+}$ & $\mathrm{a}$ & $\mathrm{a}^{*}$ & $-27 \cdot 3$ \\
$\mathbf{4}^{\prime}-\mathbf{M}$ & $-47 \cdot 5$ & $-37 \cdot 9$ & $-26 \cdot 6$ \\
\hline
\end{tabular}

*a, In plane minima on the PES

for any of the metal ions considered in the study for 1-3 systems, leading to a finite penetration barrier. The penetration barriers for $\mathbf{1}-\mathbf{M}^{+}$complexes of $\mathrm{Li}^{+}$, $\mathrm{Na}^{+}$and $\mathrm{K}^{+}$are found to be 3.3, 35.4 and $100 \cdot 2 \mathrm{kcal} / \mathrm{mol}$ respectively. For $\mathrm{Na}^{+}$and $\mathrm{K}^{+}$complexes, fairly big penetration barriers implies that passage of $\mathrm{Na}^{+}$and $\mathrm{K}^{+}$through the small cavity of dehydroannulenes would be unfavourble for both the metal ions. Understandably, $\mathrm{Li}^{+}$which is separated by the smallest distance $(0.980 \AA)$ from the plane of the dehydroannulene has the lowest barrier for penetration.

Considering 2- $\mathbf{M}^{+}$ion complexes, the binding energies follow similar trend and are slightly higher

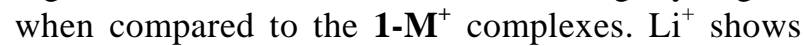
strong binding to dehydrobenzoannulene cavity at a distance of $0 \cdot 850 \AA, \mathrm{Na}^{+}$at $1.570 \AA$ and $\mathrm{K}^{+}$at $2 \cdot 281 \AA$. The corresponding binding energies are given in table 1 . As clear from the table 1 , the binding energies of the $\mathbf{2}-\mathbf{M}^{+}$complexes are higher compared to $\mathbf{1 -}$ $\mathbf{M}^{+}$and 3- $\mathbf{M}^{+}$complexes. This is probably an offshoot of greater $\pi$-electron conjugation at the central cavity in the benzodehydroannulenes. Introducing the benzene ring at the peripheral positions is found to increase the binding energy by around $9 \mathrm{kcal} / \mathrm{mol}$ compared to $\mathbf{1}-\mathbf{M}^{+}$complexes and by around $2 \mathrm{kcal} / \mathrm{mol}$ compared to $\mathbf{3}-\mathbf{M}^{+}$complexes. The penetration barriers of the $\mathbf{2}-\mathbf{M}^{+}$complexes are $2 \cdot 8,35 \cdot 8$ and $103.5 \mathrm{kcal} / \mathrm{mol}$ respectively.

Among the $\mathbf{3}-\mathbf{M}^{+}$complexes, as evident from the table 1 the binding energies of $\mathbf{3}-\mathbf{M}^{+}$ion complexes are found to be lower than for $\mathbf{2}-\mathbf{M}^{+}$. A cursory look at figure 2 reveals that displacement of the metal ions in the minimum energy structures $\mathrm{Li}^{+}$binds at a distance of $1.101 \AA, \mathrm{Na}^{+}$at $1.708 \AA$ and $\mathrm{K}^{+}$ at $2.410 \AA$ from the dehydropyridoannulene cavity. The distance between the metal ion and central cavity is slightly higher in dehydropyridoannulene- $\mathrm{M}^{+}$ complexes possibly due to the replacement of benzene ring by the pyridine ring at the peripheral position that results in slight decrease in the $\pi$-network at the central cavity. Therefore, the binding energies of 3- $\mathbf{M}^{+}$complexes are lower than in 2$\mathbf{M}^{+}$complexes. The penetration barriers of $3-\mathbf{M}^{+}$ complexes are $3 \cdot 2,35.6$ and $104.5 \mathrm{kcal} / \mathrm{mol}$ respectively. 


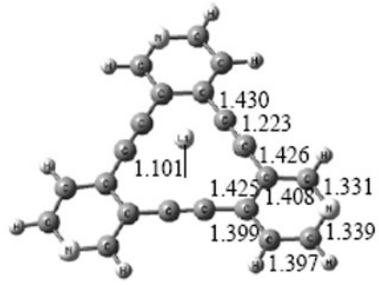

3- $\mathrm{Li}^{+}(0), \mathrm{C}_{3}$

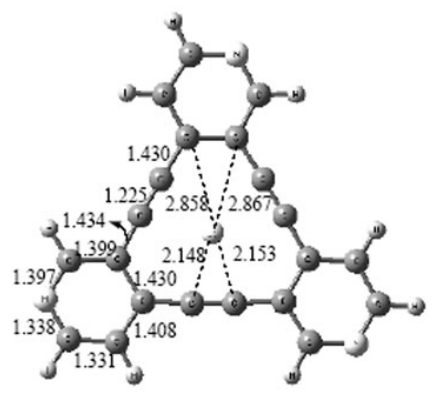

3'- $\mathbf{L i}^{+}(1), \mathrm{C}_{3 \mathrm{~b}}$
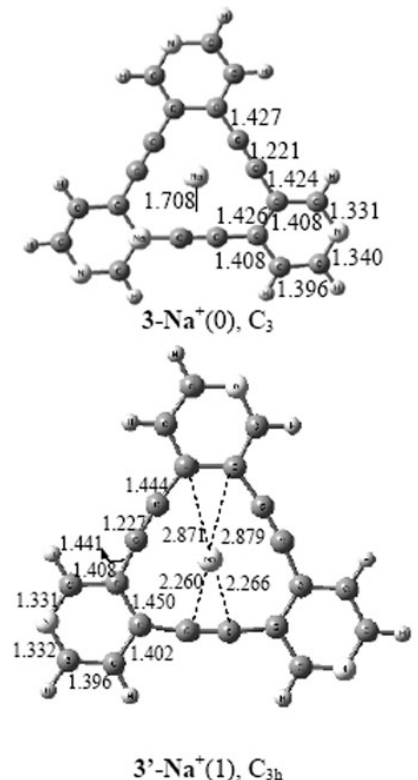

$3^{-}-\mathrm{Na}^{+}(1), \mathrm{C}_{3 \mathrm{~b}}$
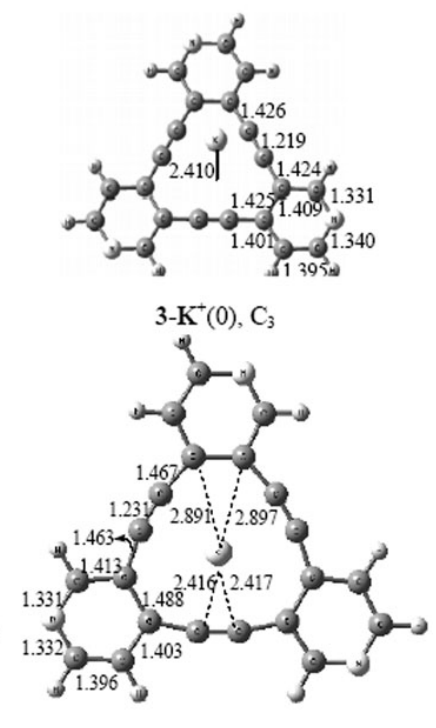

$3^{\prime}-K^{+}(1), C_{3 b}$

Figure 3. B3LYP/6-31G* optimized geometries, NIMAG in parenthesis, point groups of 3- $\mathbf{M}^{+}$and $\mathbf{3}^{\prime}-\mathbf{M}^{+}$complexes.
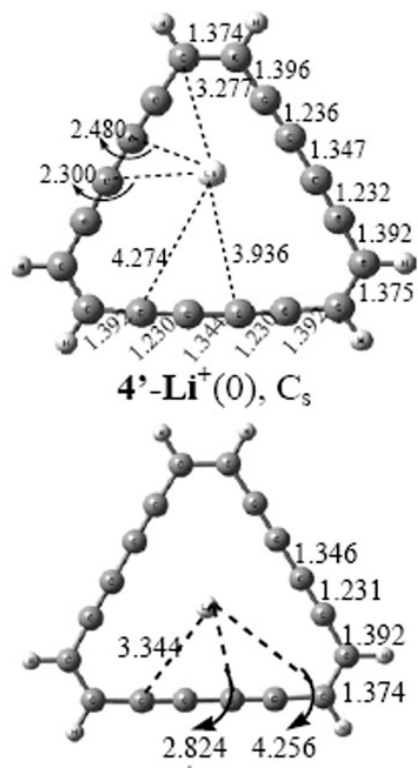

4- $\mathrm{Li}^{+}(2), \mathrm{D}_{3 \mathrm{~h}}$

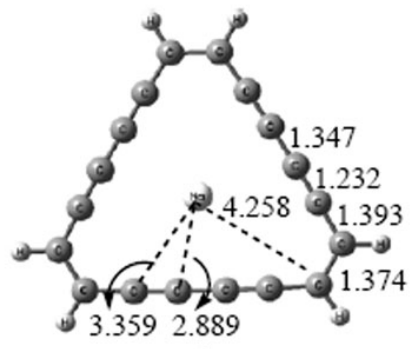

$4^{\prime}-\mathrm{Na}^{+}(0), \mathrm{D}_{3 \mathrm{~h}}$

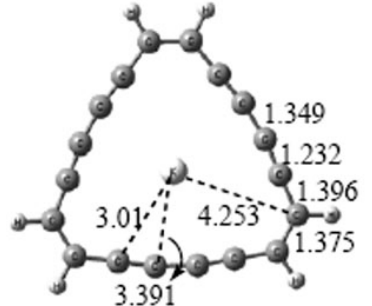

$\mathbf{4}^{\prime}-\mathbf{K}^{+}(1), \mathrm{D}_{3 \mathrm{~h}}$

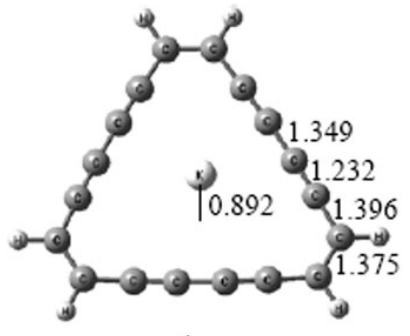

4-K $\mathbf{K}^{+}(0), \mathrm{C}_{3 \mathrm{v}}$

Figure 4. B3LYP/6-31G* optimized geometries, NIMAG in parenthesis, point groups of $\mathbf{4}^{\prime}-\mathbf{M}^{+}$and $\mathbf{4}-\mathbf{M}^{+}$complexes.

Finally, among $\mathbf{4}-\mathbf{M}^{+}$complexes the cavity size of dehydro [18] annulene is (4.3 $\AA$ ) approximately twice to the dehydro [12] annulene (where it is $2 \cdot 8 \AA$ ). When $\mathrm{Li}^{+}$ion is placed at the centroid of the cavity, $\mathbf{4}^{\mathbf{}}-\mathbf{L i}^{+}$complex is found to be a second order saddle point and the minimum energy complex cor- responds to one wherein the metal prefers to lie closer to one of the acetylenic units of the dehydroannulene system.

The $\mathrm{Na}^{+}$-dehydroannulene complex when the metal ion present at the centroid of the cavity (4$\mathrm{Na}^{+}$) is found to be minima on the potential energy 
surface. Thus the $\mathrm{Na}^{+}$ion appear to be an ideal metal to complex with the dehydro[18]annulene. In contrast, $\mathbf{4}^{\prime}-\mathbf{K}^{+}$complex is a transition state and the minimum energy complex is found when metal ion is at a distance of $0.892 \AA$ from the cavity. Thus for $4-\mathbf{M}^{+}$ complexes, the passage of the metal through the cavity is found to be much easier than other complexes.

The binding energy of the $\mathrm{K}^{+}$-dehydroannulene complex is positive for $\mathbf{1}^{\prime}-\mathbf{K}^{+}, \mathbf{2}^{\prime}-\mathbf{K}^{+}$and $\mathbf{3}^{\prime}-\mathbf{K}^{+}$, implying that these complexes are destablized when the metal is at the centroid of the cavity rather than above the plane of the central cavity. The fairly big penetration barrier implies that flow of $\mathrm{K}^{+}$through these small cavities would not be favourable for all these metal ion complexes. Similar trend is followed in the case of the $\mathrm{Na}^{+}$-dehydroannulene $\left(\mathbf{1}^{\prime}-\mathrm{Na}^{+}, \mathbf{3}^{\prime}\right.$ $\mathrm{Na}^{+}$) complex but with comparatively lower binding energies. By using the slectivity of ions for these dehydroannulene (1-4) systems, smaller metal ions can be discriminated from larger metal ions by running a variety of ions through dehydroannulene cavity.

$\mathrm{Li}^{+}$and $\mathrm{Na}^{+}$metal ions pass much more readily through the larger ring cavity size of 4 . In case of $\mathrm{K}^{+}$ the energy barrier drops drastically from the $100 \cdot 0$ $\mathrm{kcal} / \mathrm{mol}$ to $0.7 \mathrm{kcal} / \mathrm{mol}$ for $4-\mathbf{K}^{+}$complex. Our computational results illustrate that in dehydro[12]annulene (1) incorporation of six-numbered ring on to dehydroannulene ring; $(2,3)$ does not diverge the penetration barrier much.

Passage of the $\mathrm{Li}^{+}$ion through the center of the ring cavity is much easier for all the dehydroannulene rings (1-4) considered while for $\mathrm{Na}^{+}$and $\mathrm{K}^{+}$it is not easy to pass through the cavities of $\mathbf{1}, \mathbf{2}$ and $\mathbf{3}$. All the metal ions, considered in the study, appear to have low penetration barrier through [18]dehydroannulene; (4) which can be readily comprehended due to its larger cavity size.

The optimized geometrical parameters of the various metal ion complexes shown in the figures 1-4 suggest that binding of the metal either at the centroid or above the ring cavity, does not introduce significant deviation in the geometry. The geometry variation going from $\mathrm{Li}^{+}$-metal ion complex to $\mathrm{Na}^{+}$-metal ion complexes in dehydro [12] annulene (1- $\left.\mathbf{M}^{+}\right)$systems is found to be $0.001 \AA$, while the varion is $0.003 \AA$ in going from the $\mathrm{Li}^{+}$-metal ion complex to that of $\mathrm{K}^{+}$. Among all the metal ion complexes, 1$\mathbf{M}^{+}, \mathbf{2}-\mathbf{M}^{+}, 3-\mathbf{M}^{+}$and $\mathbf{4}-\mathbf{M}^{+}$complexes are found to be minima on the potential energy surface. The relative order of the distance from the metal ion to the centroid of dehydroannulne ring is $\mathrm{Li}^{+}<\mathrm{Na}^{+}<\mathrm{K}^{+}$.
In case of dehydrobenzoannulene (2) and dehydropyridoannulene (3) we have also looked at the metal ion binding to the peripheral benzene and pyridine ring. For the dehydrobenzoannulene metal complexes, a stationary point could be located only for the $\mathrm{Li}^{+}$complex. All our efforts to locate a stationary point for the $\mathrm{Na}^{+}$and $\mathrm{K}^{+}$complexes converged to $\mathbf{2 - \mathbf { M } ^ { + }}$ i.e. the structure where the metal ion is bound at the central cavity. A stationary point corresponding to the pyridine $\pi$-complex for the dehydropyridoannulene could not be obtained for any of the metal ion considered. In this case the metal ion prefers to have a sigma interaction with the lone pair of the nitrogen atom.

\section{Charge transfer analysis}

The Mulliken charges of the metal ions $\left(\mathrm{Li}^{+}, \mathrm{Na}^{+}\right.$, and $\mathrm{K}^{+}$) in all the dehydroannulene-metal ion complexes are summarized in table 2. From the data, we can gauge the positive charge that has been transferred from metal ion to the dehydroannulene cavity system during the interaction. It has been observed that the strength of interaction is proportional to the amount of charge transfer in all the metal ion complexes. The amount of charge transfer from the metal ion to the $\pi$-system decreases in the order $\mathrm{Li}^{+}>\mathrm{Na}^{+}>\mathrm{K}^{+}$. Thus, the penetration barrier of the metal ions are largely controlled by their sizes and that of the cavity of the dehydroannulenes. The strength of interaction decreases, as the ionic radius increases from lithium to potassium.

The results show that $\mathrm{Li}^{+}, \mathrm{Na}^{+}$and $\mathrm{K}^{+}$ions belong to the acceptor-type incisive compounds. Generally, the electrons move for the most part from the dehydroannulene cavity to the metal ion, and simul-

Table 2. Charges (in atomic units) of the cations in the $\mathrm{M}^{+}$-dehyderoannulene complexes calculated at B3LYP/6$311++\mathrm{G}^{* *}$ level of theory.

\begin{tabular}{|c|c|c|c|}
\hline & $\mathrm{Li}^{+}$ & $\mathrm{Na}^{+}$ & $\mathrm{K}^{+}$ \\
\hline $1-\mathbf{M}^{+}$ & $0 \cdot 052$ & 0.402 & 0.726 \\
\hline $\mathbf{1}^{\prime}-\mathbf{M}^{+}$ & $0 \cdot 275$ & $0 \cdot 354$ & $0 \cdot 507$ \\
\hline $2-\mathbf{M}^{+}$ & -0.029 & $0 \cdot 300$ & 0.630 \\
\hline $2^{\prime}-\mathbf{M}^{+}$ & $0 \cdot 480$ & 0.759 & 1.066 \\
\hline 3-M $\mathbf{M}^{+}$ & $0 \cdot 009$ & $0 \cdot 341$ & 0.670 \\
\hline $3^{\prime}-\mathbf{M}^{+}$ & $0 \cdot 457$ & 0.702 & $1 \cdot 013$ \\
\hline $4-\mathbf{M}^{+}$ & $a^{*}$ & $a^{*}$ & 0.616 \\
\hline $4^{\prime}-\mathrm{M}$ & 0.277 & 0.460 & 0.525 \\
\hline
\end{tabular}

*a, In-plane conformation is a minima on the PES 

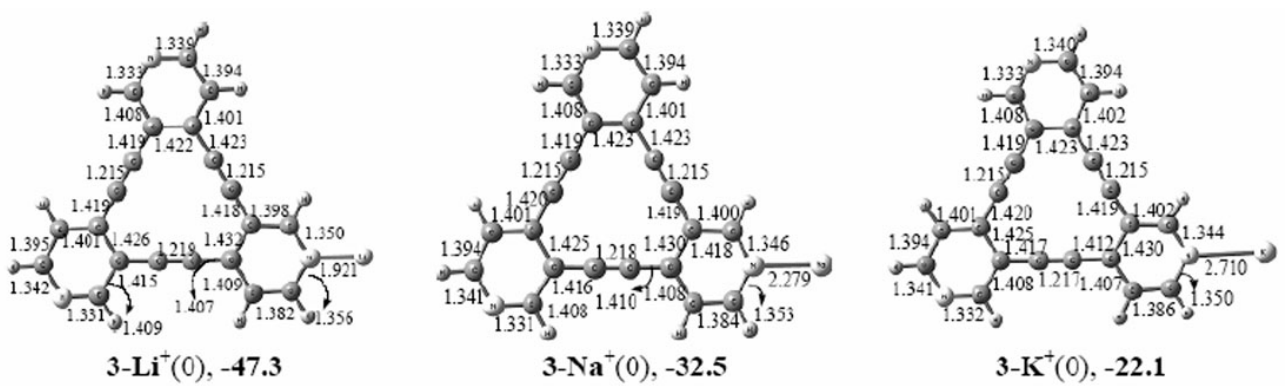

Figure 5. Pyridine $\pi$-complex for the dehydropyridoannulene optimized geometries, NIMAG in parenthesis and binding energies are given in $\mathrm{kcal} / \mathrm{mol}$.

taneously a small amount of charge is re-distributed among the carbon atoms in dehydroannulene cavity.

In the case of $\mathbf{2}-\mathbf{M}^{+}$complex, relatively the positive charge transferred from Metal $\left(\mathrm{Li}^{+}\right)$to $\pi$-system in $\mathbf{2}-\mathbf{L i}^{+}$complexes is more than the charge transferred in remaining complexes and the corresponding interaction energy is $-61.7 \mathrm{kcal} / \mathrm{mol}$ which is very high. In case of the $\mathbf{2}^{\prime}-\mathbf{K}^{+}$and $\mathbf{3}^{\prime}-\mathbf{K}^{+}$complexes the charge transferred from metal $\left(\mathrm{K}^{+}\right)$to $\pi$-system is lower, and the corresponding binding energies are 73.6 and $85.3 \mathrm{kcal} / \mathrm{mol}$ respectively.

\section{Conclusions}

The present computational study provides the theoretical evidence for the strong binding of the metal ions to dehydroannulenes and propose that dehydroannulenes have potential possible applications as molecular sieves and also as separating agents. The size of the metal ion and the cavity size of the dehydroannulenes decide the extent of penetration barrier of the metal ions through the cavity of later. Their robust $\pi$-framework, which allows it to bind to a range of ionic fragments, also can be exploited for potential applications in the design of new materials. The tenability of the physico-chemical properties and the recent successes in the synthetic methodologies to access a variety of dehydroannulenes and their analogs make them potentially interesting class of molecules for the molecular separation and sieving applications.

\section{Acknowledgments}

We dedicate this paper to Professor Debashsis Mukherjee on the occasion of his 60th birthday. B S thanks Council of Scientific and Industrial Research
(CSIR), New Delhi for a senior research fellowship. Mrs K Vani is thanked for her initial involvement in the project.

\section{References}

1. Baughman R H, Eckhardt H and Kertesz M $1987 \mathrm{~J}$. Chem. Phys. 876687

2. Kennedy R D, Lloyd D and McNab H 2002 J. Chem. Soc., Perkin Trans 11 1601; Youngs W J, Tessier C A and Bradshaw J D 1999 Chem. Rev. 993153

3. Ohkita M, Kawano M, Suzuki T and Tsuji T 2002 Chem. Commun. 3054

4. Baxter P N W and Dali-Youcef R 2005 J. Org. Chem. 704935

5. Marsden J A and Haley M M 2005 J. Org. Chem. 70 10213

6. Marsden J A, Palmer G J and Haley M M 2003 Eur. J. Org. Chem. 2355

7. Tobe $Y$, Ohki I, Sonoda $M$, Niino $H$, Sato $T$ and Wakabayashi T 2003 J. Am. Chem. Soc. 125 5614; Boydston A J, Laskoski M,. Bunz U H F and Haley M M 2002 Synlett. 981; Mitzel F, Boudon C, Gisselbrecht J.-P, Gross M and Diederich F 2002 Chem. Commun. 2318; Gallagher M E and Anthony J E 2001 Tetrahedron Lett. 42 7533; Bunz U H F and Enkelmann V 1999 Chem. Eur. J. 5263

8. Nishinaga T, Nodera N, Miyata Y and Komatsu K 2002 J. Org. Chem. 676091

9. Kondo M, Nozaki D, Tachibana M, Yumura T and Yoshizawa K 2005 Chem. Phys. 312289

10. Baxter P N W 2004 J. Org. Chem. 691813

11. Toyoto S, Iyoda M and Toda F 2002 Annu. Rep. Prog. Chem., Sect. B 98359

12. Wan W B and Haley M M 2001 J. Org. Chem. 663893

13. Grima J N and Evans K E 2000 Chem.Commun. 1531

14. Narita N, Nagai S, Suzuki S and Nakao K 2000 Phys. Rev. B62 11146

15. Baxter P N W 2003 Chem. Eur. J. 9 2531; Campbell K, McDonald R, M. Ferguson J and Tykwinski R R 2003 Organometallics. 22 1353; Campbell K, McDonald R, and Tykwinski R R 2002 J. Org. Chem. 67 1133; Campbell K, McDonald R, Branda N R and Tykwinski 
R R 2001 Org. Lett. 3 1045; Sun S S and Lees A J 2001 Organometallics 20 2353; Bosch E and Barnes C L 2000 Organometallics. 19 5522; Tobe Y, Nagano A, Kawabata K, Sonoda M and Naemura K 2000 Org. Lett. 2 3265; Baxter P N W 2002 Chem. Eur. J. 8 5250; Henze O, Lentz D, Schafer A, Franke P and Schluter A D 2002 Chem. Eur. J. 8 357; Baxter P N W 2001 J. Org. Chem. 66 4170; Henze O, Lentz D and Schluter A D 2000 Chem. Eur. J. 6 2362; Grave C, Lentz D, Schafer A, Samori P, Rabe J P, Franke P and Schluter A D 2003 J. Am. Chem. Soc. 125 6907; Baxter P N W 2003 Chem. Eur. J. 95011

16. Reddy A S and Sastry G N 2005 J. Phys. Chem. A109 8893

17. Vijay D and Sastry G N 2006 J. Phys. Chem. A110 10148
18. Reddy A S, Vijay D, Sastry G M and Sastry G N 2006 J. Phys. Chem. B110 2479; Reddy A S, Vijay D, Sastry G M and Sastry G N 2006 J. Phys. Chem. B110 10206

19. Reddy A S, Sastry G M and Sastry G N 2007 Proteins: Structure, Function and Bioinformatics 671179

20. Reddy A S, Zipse H and Sastry G N J. Phys. Chem. B111 11546

21. Priyakumar U D, Punnagai M, Mohan G P K and Sastry G N 2004 Tetrahedron 603037

22. Priyakumar U D and Sastry G N 2003 Tetrahedron Lett. 446043

23. Frisch M J et al. 2003 Gaussian 03 (Revision B.5) (Pittsburgh: Gaussian, Inc)

24. Reed A E, Curtis L A and Weinhold F 1988 Chem. Rev. 88899 